\title{
Systematic Construction of the Inheritance and Operation Mechanism of Minority Traditional Sports
}

\author{
Shumin Zhang ${ }^{1}$, Wei Guo ${ }^{1}$ \\ ${ }^{1}$ Jiangxi University of Science and Technology, Nanchang, Jiangxi, 330100
}

Keywords: Traditional sports of ethnic minorities; inheritance and operation mechanism; construction

\begin{abstract}
The long historical accumulation has given the profound cultural connotation of the traditional sports culture of ethnic minorities in China. It not only has important historical reference value and cultural value, but also provides more reference for people to carry out fitness and entertainment. However, with the continuous development of society, the survival of traditional sports of ethnic minorities is also facing more and more challenges. The traditional sports culture of a large number of outstanding ethnic minorities is gradually alienating and even on the verge of loss. Starting from the problems faced by the inheritance of traditional sports culture of ethnic minorities in China, this paper puts forward some strategies for constructing the system of traditional ethnic minority heritage sports in order to promote the better inheritance and development of traditional sports culture of ethnic minorities in China.
\end{abstract}

\section{Introduction}

Traditional sports of ethnic minorities belong to an important cultural carrier, a kind of culture gradually formed in the life and production of ethnic minorities. It is also an important educational carrier for the inheritance of ethnic minority cultures, and it is one of the development processes of minority cultures. A gem. The operational mechanism refers to the functions, structures, and relationships between various factors that affect the regular movement of human society, as well as the functions, effects, operational mechanisms, and mechanisms of those factors that function, influence, and constrain. Relevant systems or guidelines. At present, the inheritance of traditional sports of ethnic minorities in China is facing many difficulties, which seriously hinders the development of traditional sports culture of ethnic minorities. Therefore, it is urgent to construct an effective system of inheritance and operation mechanism.

\section{Problems in the inheritance of traditional sports culture of ethnic minorities in China}

\subsection{Theoretical research needs to be improved}

The traditional sports culture of ethnic minorities in China mainly comes from the life and production practices of ethnic minorities. It has not yet formed a relevant theoretical system and construction theory, and it is doomed to its non-framework vulnerability. Therefore, if we want to ensure the smooth and effective inheritance of the traditional sports culture of ethnic minorities in China, we must construct a relevant theoretical system. However, at present, the theoretical research on this aspect in China is not mature enough, and a perfect inheritance mechanism has not yet been formulated. The developed disciplinary system is even more fragile, which further increases the difficulty of inheriting the traditional sports culture of ethnic minorities.

\subsection{The foundation of the traditional sports culture of ethnic minorities is being eroded}

With the rapid development of the national economy, the social model has undergone a tremendous transformation. The traditional sports culture foundations of ethnic minorities based on specific economies and societies have also been severely eroded. For example, religious traditional festivals, folk festivals and other traditional sports activities of ethnic minorities are positive. 
Gradually eroded by the market economy, and even some are on the verge of loss, and in the long run, will inevitably cause irreparable losses [1].

\subsection{The traditional sports culture of ethnic minorities is marginalized}

Foreign sports culture has greatly affected the traditional sports culture of ethnic minorities in China, especially the implementation of the Olympic Movement. As a result, many traditional sports in China have been gradually replaced by Western sports. The traditional sports culture of ethnic minorities has gradually become marginalized. [2]. With the continuous deepening of western sports culture thoughts, the traditional sports culture of ethnic minorities in China has gradually lost its living soil, and the difficulty of inheritance has become more and more serious.

\section{The system construction strategy of ethnic minority traditional sports inheritance and operation mechanism}

The planning system mainly involves the macro-management level. The construction of the planning system is mainly responsible for the cultural and sports bureaus, government agencies, scientific research institutions and minority religious affairs bureaus. The construction of the planning system is mainly to plan the inheritance of traditional sports of ethnic minorities. For example, in the process of inheriting the traditional sports culture of ethnic minorities in Guilin, the Guilin Municipal Sports Bureau, the Guilin Municipal Ethnic and Religious Committee, the Guilin Municipal Government, the Guilin Municipal Tourism Bureau, and the universities in Guilin should be actively involved in the construction of the planning system. Planning the inheritance objectives of traditional sports culture of ethnic minorities in the region, and the form of inheritance, inheritance environment, inheritance requirements and inheritance standards and plans should be included in the planning content [3]. The above institutions should strengthen communication and collaboration, and the entire process from setting goals, optimizing goals to implementing goals must be comprehensive and careful planning.

All the management institutions and organizations involved in the inheritance of traditional sports of ethnic minorities belong to the organizational system. Organizations include micro and macro categories. Among them, ethnic and religious committees, local governments, individual associations, sports bureaus, and national traditional sports management centers are all micro-level organizations; the National Ethnic Affairs Commission and the state Organizations such as the General Administration of Sports are organizations at the macro level. The organizational system for the inheritance of traditional sports of ethnic minorities should include the following contents: in accordance with the planning requirements of the National Ethnic Committee and the State Sports General Administration, the regional ethnic and religious affairs committees and sports bureaus should take the lead in setting up municipal-level national traditional sports management centers and local The individual associations of traditional sports of various nationalities are continuously adjusted and optimized. At the same time, it is required that the traditional sports inheritance organization system of ethnic minorities in various regions regularly carry out some traditional sports activities for ethnic minorities, such as various traditional folk sports competitions, performances, traditional sports games for ethnic minorities, traditional sports competitions of ethnic minorities in various villages, and different ethnic minorities. Traditional sports single competitions, etc. [4]. In addition, we should actively seek the assistance of local colleges and universities, and strive to introduce the traditional sports culture of ethnic minorities into the campus and integrate them into the cultivation of talents and scientific research so as to better inherit the traditional sports culture of ethnic minorities; With the support of the local tourism bureau, the traditional sports activities of ethnic minorities will be carried out in local scenic spots or parks to expand their influence and attract more people to pay attention to the inheritance of traditional sports culture of ethnic minorities.

All the security systems and security systems involved in the inheritance of traditional sports of ethnic minorities are collectively referred to as the security system. The security system mainly consists of three parts: first, funding guarantee; second, talent security; third, policy guarantee. 
From a local perspective, the relevant provisions, regulations, special funds, and special personnel are all prerequisites for ensuring the effective transmission of traditional sports of ethnic minorities. From the perspective of the state, policies, laws and regulations, funding guarantees and talent guarantee are important foundations for carrying forward the traditional sports of ethnic minorities and promoting the unity of all nationalities. Therefore, in order to better carry forward and carry forward the traditional sports of ethnic minorities in China, we should strengthen the construction of various security systems. Talent protection is an indispensable link in inheriting and carrying forward the traditional sports of ethnic minorities. In terms of talent protection, relevant departments should attach great importance to the development of human resources and the cultivation of talent cultivation systems for ethnic minority traditional sports. Although there are many traditional sports inhabitants and some folk artists in the country, they play an important role in inheriting and carrying forward the traditional sports of ethnic minorities. However, China is facing a paradox in the cultivation of traditional sports talents of ethnic minorities. Affected by social and economic factors, many folk artists have fallen into the embarrassing situation of "nothing to teach". Therefore, it is suggested that the traditional sports culture of ethnic minorities should be introduced into the campus, and the traditional sports of ethnic minorities should be inherited and promoted through the talent cultivation mode and scientific research channels of the colleges. In terms of funding support, it is recommended that the government appropriately increase the capital investment in inheriting traditional sports of ethnic minorities and strive to create good conditions for inheritance. In terms of policy support, we should closely follow the requirements of national policies and formulate a relatively loose national policy. At the same time, we must conscientiously implement and strictly control the "song" and "tight" scales. National sports policies are no exception, and must not be in the form. Indiscriminately.

The evaluation system mainly evaluates the development status of traditional sports activities of ethnic minorities, such as the security level, organizational level and planning level, etc., which should be used as the evaluation content of the evaluation system. At the same time, the risk, significance and goals of the traditional sports activities of ethnic minorities are implemented. Etc. is also an evaluation indicator that cannot be ignored. In order to realize the all-round inheritance and promotion of traditional sports of ethnic minorities, it is recommended that ethnic and religious committees, tourism departments, sports departments, education departments, folk artists and grassroots in various regions actively participate in the construction of the evaluation system, and strictly supervise and manage minority traditions. The implementation of sports activities, and the development of a comprehensive reward and punishment system. For those who work hard, they should increase their punishment; and those who perform well should be given appropriate rewards to make the rewards and punishments clear.

\section{Conclusion}

In summary, at present, there are many problems in the inheritance of traditional sports of ethnic minorities in China. For example, theoretical research needs to be improved, the foundation of traditional sports culture of ethnic minorities is being eroded, and the traditional sports culture of ethnic minorities is marginalized. Therefore, it is very necessary to construct Minority traditional sports inheritance and operation mechanism system to promote the better inheritance and promotion of traditional sports of ethnic minorities. The research in this paper is not comprehensive enough. The construction of the system of ethnic minority traditional sports inheritance and operation mechanism is a topic worthy of in-depth discussion by all relevant practitioners.

\section{References}

[1] QU Zhibin, GU Xiaoyan. Systematic Construction of the Inheritance and Operation Mechanism of Traditional Sports of Ethnic Minorities in China[J]. Journal of Beijing Sport University, 2015(04):45-51. 
[2] Tan Xiaochun, Ma Xue. Analysis of the Inheritance and Protection of National Traditional Sports Culture by Minority Community Education[J]. Wushu Research, 2018(07): 75-77.

[3] Zhang Na. Research on the Protection and Cultivation Mechanism of the Inheritors of Achang Traditional Sports Culture[J]. Sports World (Academic Edition), 2018(05): 73-74.

[4] LIN Weixian, SUN Hong, LI Zhuang, ZHOU Jinguo. Research on the Inheritance and Development of Sports Intangible Cultural Heritage__Taking Nanzhi Boxing as an Example[J]. Journal of Guangzhou Physical Education Institute,2018(03):40-44. 